\title{
The role of leaf petiole in photoperiodic induction of flowering
}

\author{
Z. VONDRÁKOVÁ and J. KREKULE \\ Institute of Experimental Botany, Academy of Sciences of the Czech Republic, \\ Rozvojová 135, CZ - 16502 Praha 6 - Lysolaje, Czech Republic
}

\begin{abstract}
Explants of Chenopodium rubrum, a short-day plant, were decapitated and exposed to floral inductive treatment, and the extent of flowering of axillary buds was afterwards assessed. Isolated buds never responded to induction, whercas the presence of the petiole of the subtending leaf already assured a high degree of flowering. We may assume either that the petiole is the receptor organ of the photoperiodic signal or that its transporting role is indispensable.
\end{abstract}

Additional key words: Chenopodium rubrum, in vitro, organ correlations, short-day plant.

Flowering in explants of photoperiodic plants has been investigated with the aim of finding out whether isolated apices of induced plants are capable of floral development and when their commitment to flowering occurs (e.g. McDaniel et al. 1991). In a few other cases the inducibility of explants has been explored (Raghavan and Jacobs 1961, Vondráková 1992). The latter approach implicates the problem of the receptor organs for the photoperiodic signal and the minimal size of explants responding to floral induction. We have found recently that, besides leaves and cotyledons, the hypocotyl can also be involved in perception of photoperiodic treatment (Vondráková and Krekule - unpublished results). The aim of the experiments presented here was to investigate whether other parts of the stem are also responsive to floral induction and to what extent an explant may be reduced and still not lose the capacity for induction.

Three-week-old Chonopodium nubrum L. plants, which are inducible to flowering by one dark period (Ullmann et al. 1985), were used to address this problem. Their responsiveness to flower inductive treatment was tested in vitro using various 
explants restricted either to axillary buds with or without subtending leaves or also including adjacent internodes.

The plants were cultivated in vitro under continuous illumination (white fluorescent tubes, Tesla 811 , irradiance at plant level of $184 \mu \mathrm{mol} \mathrm{m}^{-2} \mathrm{~s}^{-1}$ ), and temperature of $20 \pm 1{ }^{\circ} \mathrm{C}$ on LS medium (Linsmaier and Skoog 1965) with $2 \%$ sucrose but without growth regulators. The plants had already differentiated 8 to 9 pairs of leaves and leaf primordia, the four oldest leaves being fully developed. The cotyledons were senescing. The apical part of the plants, containing a terminal bud, third leaf pair and a part of the stem adjacent to it, was explanted (basic explant). Axillary buds were already developed at the leaves node of the third pair. The segments used in the experiments were derived from these basic explants and their appearance is schematically described within the results of each experiment (Figs. 1 and 2).

The segments were grown on the same medium as the intact plants and were exposed, immediately after explantation, to one or three short days ( $16 \mathrm{~h}$ of darkness $+8 \mathrm{~h}$ of light) and then returned to continunus illumination for further $7 \mathrm{~d}$. The degree of flowering of the terminal and axillary buds was evaluated using a stereomicroscope. The experiments were performed five times and there were 15 to 20 segments in each treatment.

The apical buds of the basic explants (control) treated with three short days in the first experiment flowered up to $100 \%$ (Fig. 1). Both axillary buds were vegetative, possibly due to apical dominance. The axillary buds from the respective segments developed considerably after decapitation, and flowered nearly to the same degree following exposure to three short days (Fig. 1). The upper or lower position did not significantly affect the percentage of their flowcring. Morcover, the removal of lcaf blades from the segments did not greatly influence the degree of flowering. This

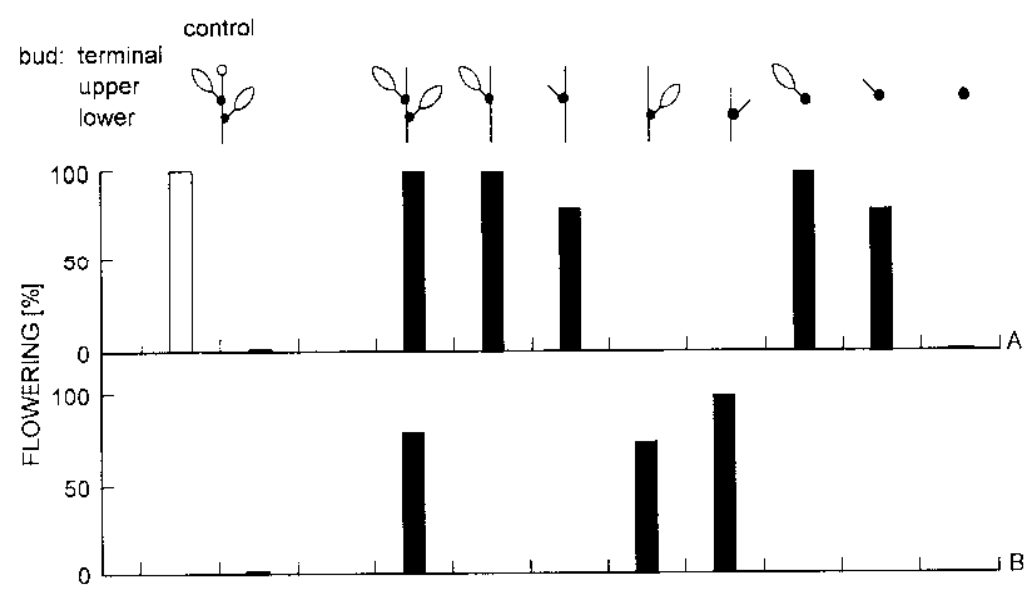

Fig. 1. Flowering of buds on the segments treated by 3 short days ( $16 \mathrm{~h}$ of darkness $+8 \mathrm{~h}$ of light). Open column - flowering of terminal buds on the control segments, closed columns - flowering of axillary buds ( $A$ - upper buds, $B$ - lower buds). 
applied equally to segments consisting of axillary bud and subtending leaf. With leaf blade removed the petiole itself still assured $80 \%$ of flowering. Isolated buds were, however, never inducible to flowering by short days, this holding true for all the experiments performed. In the second experiment the photoperiodic treatment was shortened to one dark period. The percentage of flowering of terminal buds of control explants dropped to $25 \%$, the axillary buds again being completely vegetative (Fig. 2). A similar degree of flowering was observed with decapitated segments only at upper position of axillary bud. The lowered level of florigenic signal due to just one day is possibly impaired by a stronger degree of apical dominance at the lower position. The removal of leaf blade did not lead to a decrease in percentage of flowering in buds isolated together with their subtending leaves. This again confirmed the role of petiole as an indispensable factor in floral induction of Chenopodium rubrum explants. All axillary buds, irrespective of their position, remained vegetative in segments grown under continuous illumination.

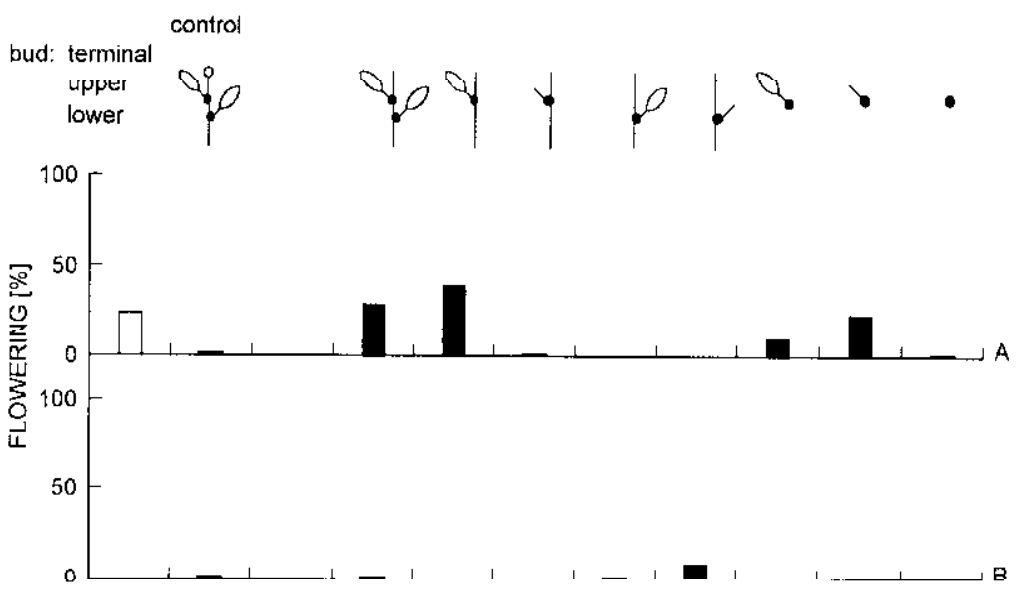

Fig. 2. Flowering of buds on the segments treated by 1 short day ( $16 \mathrm{~h}$ of darkness $+8 \mathrm{~h}$ of light). Open column - fluwering of terminal buds on the control segments, closed columns - flowering of axillary buds ( $A$ - upper buds, $B$ - lower buds).

The results reported above are in agrecment with our previous findings indicating that isolated buds do not respond to photoperiodic treatment by flower initiation (Vondráková 1992, Vondráková and Krekule - unpublished). It is impossible to decide whether the bud lacks the sensitivity to the pholoperiodic signal, possibly due to its subcritical size, or whether its induced state is not expressed while the bud is isolated from the rest of the plant. Literature data suggest both posssibilities. Isolated apical buds were succesfully induced to flower in Xanthium (Jacobs and Suthers 1974) and in Perilla (Raghavan and Jacobs 1961). On the other hand, in apices isolated from photoperiodically induced Lolium the floral differentiation requires exogenous compounds such as gibberellins and sugars (McDaniel et al. 1991). 
Hence, such compounds provided in the whole plant may be absent in our system of isolated buds. A positive response to the first question also implies the flowering promotive role of the petiole as a receptor organ for the photoperiodic signal, similarly as can be explained the floral enhancing effect of the hypocotyl (Vondráková and Krekule -unpublished). The second case would be consistent with the possihility that the transporting function of the petiole might be important. However, the fact that the removal of the leaf, i.e. leaf blade and petiole, during photoperiodic treatment prevented induction (Pavlová et al. 1991) makes the receptory function of petiole unlikely (i.e. we consider it more probable that the isolated bud itself may be induced but be incapable of expressing the induced state). This draws attention to the nature of substances essential for flower differentiation in Chenopodium rubrum and to the role played hy various transporting systems in supplying the meristem. The in vitro system provides the possibility to test these alternatives and will be further investigated.

\section{References}

Jacobs, W.P., Suthers, F.B.: Effects of leaf excision on flowering of Xanthium apical buds in culture under inductive and non-inductive photoperiods. - Amer. J. Bot. 61: 1016-1020, 1974.

Linsmaier, F.M., Skong, F.: Organic growth factor requirements of tobacco tissue cultures. Physiol. Plant. 18: 100-127, 1965.

McDaniel, C.N., King, R.W., Evans, L.T.: Floral determination and in vitro floral differentiation in isolated shoot apices of Lolium temulentum L. - Planta 185: 9-16, 1991.

Pavlová, L., Krekule, J., Součková, D.: Urgan correlations and flowering in Chenopodium rubrum L. - Biol. Plant. 33: 97-104, 1991.

Raghavan, V., Jacobs, W.P.: Studies on the floral histogenesis and physiology of Perilla. II. Floral induction in cultured apical buds of $P$. frutescens. - Amer. J. Rot 48: 751-760, 1961.

Ullmann, J., Seidlová, F., Krekule, J., Pavlová, L.: Chenopodium rubrum as a model for testing the flowering effects of PGRs. - Biol. Plant. 27: 367-372, 1985.

Vondráková, Z.: The effect of 6-benzylaminopurine on in vitro flowering of Chenopodium rubrum. - In: Kaminek, M., Mok, D.W.S., Zažímalová, E. (ed.): Physiology and Biochemistry of Cytokinins in Plants. Pp. 385-387. SPB Academic Publishing, The Hague 1992. 